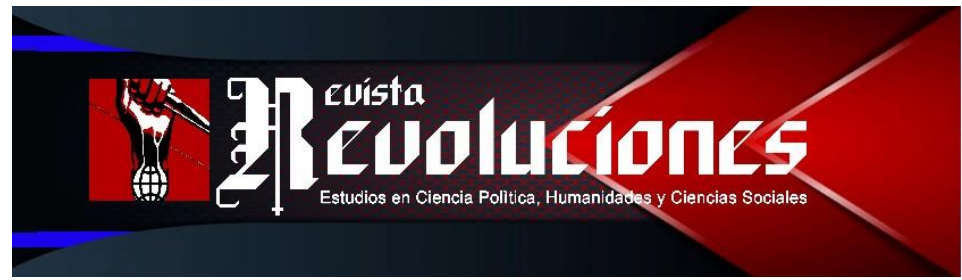

\title{
EDITORIAL
}

\section{UN FANTASMA RECORRE EL PERÚ DEL BICENTENARIO: LECCIONES Y VOLUNTAD POPULAR EN LAS ELECCIONES DE 2021}

\section{A ghost travels through bicentennial Peru: lessons and popular will in the 2021 election}

\author{
Jesús Wiliam Huanca-Arohuanca ${ }^{1}$ \\ UNIVERSIDAD NACIONAL DE SAN AGUSTÍN DE AREQUIPA \\ PERÚ \\ jhuancaar@unsa.edu.pe \\ https://orcid.org/o00o-0002-7353-1166
}

DOI: https://doi.org/10.35622/j.rr.2021.03.001

Recibido: 11-IV-2021 / Aceptado: 14-IV-2021 / Actualizado: 2O-IV-2021

\begin{abstract}
Resumen
Es doloroso ver que nuevamente el Perú sea el escenario de una lucha ideológica entre la izquierda en ascenso y una derecha radical con miedo de perder su hegemonía sobre la clase periférica del cual no tenían ni idea de su existencia, hasta que las elecciones de 2021 develaron que aquella mayoría excluida seguía respirando, ahora más que nunca y eligiendo a un candidato muy semejante a ellos. $\mathrm{El}$ presente tiene por objetivo analizar las lecciones aprendidas durante el proceso electoral y la voluntad popular que desea cambios sustanciales para que la democracia sea lo que es, próximo a cumplir el bicentenario.
\end{abstract}

\footnotetext{
${ }^{1}$ Filósofo político e investigador social en el departamento de Filosofía con mención en Ética y Filosofía Política por la Universidad Nacional de San Agustín de Arequipa [UNSA], Perú. Maestrante en la facultad de Ciencias Jurídicas en Derecho Procesal y Administración de Justicia por la Universidad Católica de Santa María [UCSM], Perú. Docente de Ciencias Sociales, Sociólogo y maestrante en Investigación y Docencia Universitaria por la Universidad Nacional del Altiplano [UNA-P], Perú. En la actualidad dirige la Revista Revoluciones: Estudios en Ciencia Política, Humanidades y Sociales. Así mismo, es revisor de la Revista Educación y Sociedad de la Universidad de Ciego de Ávila Máximo Gómez Báez, Cuba y la Revista Innova Educación del Instituto Universitario de Investigación [INUDI], Perú. Áreas que maneja: Filosofía, Ciencia Política, Ciencias Sociales, Investigación Cualitativa, Políticas Educativas para el Desarrollo Sostenible y Sustentable, Historia Latinoamericana, Sociología y Gestión Pública. Últimas publicaciones: Caleidoscopio social al Covid-19: pánico y desesperación en tiempos de aislamiento [2020] y Narrativas de guerra y resistencia: participación de la mujer austral del Perú en la Guerra del Pacífico [2021]. Impacto académico: tiene publicaciones a nivel internacional en SCOPUS, Web of Science y Scielo que recae en países como; Colombia, Chile, España, Ecuador, Venezuela, Costa Rica y Cuba; a nivel local tiene publicaciones en todas las regiones de la República Democrática del Perú.
} 
Palabras Clave: Izquierda, política, ideología, democracia, revolución.

\section{Abstract}

It is painful to see Peru once again be the scene of an ideological struggle between the rising left and a radical right in fear of losing its hegemony over the peripheral class of which they had no idea of its existence. until the 2021 elections revealed that the excluded majority was still breathing, now more than ever and choosing a candidate very similar to them. The present aims to analyze the lessons learned during the electoral process and the popular will that wants substantial changes to make democracy what it is, near the bicentenary.

Keyword: Left, politics, ideology, democracy, revolution.

\section{INTRODUCCIÓN}

Con proximidades al bicentenario, la sociedad peruana enfrenta una enfermedad peligrosa que ha provocado la muerte de miles de personas, y a la vez, vive una incertidumbre política que retrotrae el enfrentamiento de dos clases que nunca se encontraron. En ese criterio, en el Perú de hoy, aún sigue vigente la denominada clase baja/clase alta, izquierda/derecha, abajo/arriba, indígena/criollo, pobres y ricos. Tipificación de clases que resulta de una democracia débil, falta de institucionalidad, perversión de la ética, deficiente educación, carencia de partidos políticos que verdaderamente representen al país y la corrupción de un modelo que no funciona como se pone que funcione. Por ello, hablar de política en el Perú es hablar de corrupción y robo, claro ejemplo es ver que casi todos los que hacen y han realizado política, están con una sentencia por violar la ley.

Ahora bien, a pesar de los múltiples intentos de la clase dominante de mostrar al Perú ante la comunidad internacional como un país sólido que ha dejado en el pasado el odio al indio y las diferencias de raza, resulta una falacia. Como se sabe, los acontecimientos actuales han develado la verdadera imagen de la clase racista con resentimiento hacia el hombre andino y hacia el pobre. Esa clase conservadora del odio, esperaba que las elecciones de 2021 consoliden su ira visceral ofertando candidatos como: De Soto, Aliaga, Guzmán y Fujimori. Sin embargo, la historia fue otra, y las encuestadoras que colocaban a sus candidatos favoritos, se equivocaron como siempre.

La clase conservadora habitual, no está en la capacidad de construir una democracia con sostenibilidad e igualdad para todos los peruanos (Huanca-Arohuanca \& Pilco, 2021; HuancaArohuanca, 2020; 2021; Tineo-Zaga et al., 2021). Ellos están en el poder para que nada cambie y que la diferencia de clases siga vigente por los próximos 200 años. La derecha radical insulta, miente, odia, minimiza, manipula y roba la subjetividad de los peruanos, no están para construir, están para delinquir y echar por tierra todos los intentos de soberanía de la población que dio su voto al candidato de Perú Libre.

Por todo lo anterior es que se habla de izquierda, una ideología evidentemente esperanzador, culto y sobre todo más democrático que la derecha radical consagrado como tal. El hecho de que Pedro Castillo haya pasado a la segunda vuelta no es producto de una casualidad, más bien es resultado de que algo anda mal en el Perú. Es más, tener candidatos como Acuña, Forsyth, Aliaga y Keiko es signo de que académicamente estamos en la nada y que el sector educacional no ha sido lo suficientemente eficaz para enseñar que esos personajes ni siquiera deberían llamarse políticos.

\section{DESARROLLO}

La dicotomía existente entre la izquierda en ascenso y la derecha radical, no es un suceso reciente para la historia republicana. Los que han gobernado y manejado el Perú desde el proceso de 
Independencia, curiosamente se han ubicado del lado de los que recrean el odio y el racismo como patrones de dominación, salvo algunas excepciones. Así que, soslayar tales acontecimientos puede ser peligroso para la misma democracia e incluso para la libertad que es el máximo imperativo de los pueblos.

Lo sucedido en el Perú en las elecciones de 2021 primera fase, es una clara expresión de la voluntad popular silenciado por la élite conservadora-centralista-racista sin algún planteamiento novedoso. La gente de a pie ve como posibilidad el cambio sustancial a favor de ellos, cuando ven a un hombre que puede ser uno de ellos, un hombre que representa la humildad, la sencillez y la ideología que por mucho tiempo se había dejado de hablar. Sin embargo, a la derecha radical todo le huele a putrefacción cuando se habla de cambio, ellos no entienden que el Perú también es la multiplicidad de gente que sirve a la estructura de poder como base primordial de subsistencia (Huanca-Arohuanca, 2019; 2019b; 2020b; Huanca-Arohuanca \& Geldrech, 2020).

La gente que odia al subalterno y que es incapaz de reconocerlo de igual a igual, solo ve una marea roja aproximándose y que supuestamente va a destruir la muy aclamada democracia, cuando en el fondo la derecha radical es la que desde un inicio fulminó y pervirtió los fundamentos de la democracia y la libertad. De manera que, el fantasma que otra vez despierta para romper la comodidad de la clase conservadora, recorre todo el Perú, esta vez llevará al punto decisivo si el país cambia de modelo o sigue bajo la tutela de la política internacional orquestado desde Washington D.C.

En esa connotación, las elecciones generales de 2021 han ocasionado las siguientes lecciones al país multicultural:

- Todavía sigue vigente la lucha ideológica entre la izquierda en ascenso y la derecha radical.

- Se purifica con mayor fuerza el racismo y la discriminación por los sectores del centralismo limeño.

- La masa de excluidos pide cambios urgentes en el país de todas las sangres.

- La educación no ha sido lo suficientemente estricto como para enseñar que los sujetos con vínculos a la mafia y a la corrupción, no son dignos de representar a la mayoría.

- Los medios de comunicación no cumplen el papel que tienen, por el contrario, mienten, agreden, desinforman y obstaculizan la libertad de expresión.

- La cultura milenaria de los peruanos ha sido profanada por los personajes públicos de la farándula y ciertos opinólogos de poca relevancia.

- Los idiomas ancestrales han sido burlados por la gente que no tiene la menor idea de cómo funciona este signo lingüístico.

- Las políticas económicas como planteamiento de los candidatos de la derecha radical, siguen siendo ineficientes para acortar la brecha entre ricos y pobres.

- Se ha encontrado gente enajenada, que a pesar de las carencias que presentan, dan su apoyo a sectores que nunca verán.

- La pandemia a desarropado todos los problemas que estaban cubiertos de cierto cinismo y populismo por los gobiernos de turno.

- El cambio constitucional es cada vez más visible a puertas del bicentenario.

Con esos problemas que frenan el avance del país, no es posible pensar otra vez en gobiernos de la derecha radical y menos aún en sus representantes que solo significan: nada. El país necesita de sujetos con posibilidades de llegar a la mayoría silenciada, que hoy, han manifestado en las urnas el cambio sustancial, confiando en el candidato de Perú Libre que ha obtenido el 19\% de la población electoral. Ahora bien, pensar en una idea de izquierda cuando eres peruano resulta sensato y culto, a pesar de los ataques provenientes de una clase en colapso con cierto complejo de superioridad hacia la gente contraria a su pensamiento. 


\section{UN FANTASMA RECORRE EL PERÚ DEL BICENTENARIO: LECCIONES Y VOLUNTAD \\ POPULAR EN LAS ELECCIONES DE 2021 \\ ISSN: 2710-0499 ISSN-L: 2710-0480}

La pandemia ha sido el filtro necesario para ver de cerca que en el Perú todavía se mantiene el resentimiento hacia la gente que se gana la vida en las calles, a pesar de una enfermedad que le espera para llevarle al tártaro (Huanca-Arohuanca, 2020c; 2020a; Huanca-Arohuanca \& Núñez, 2020). El peruano que realmente representa lo que es ser patriota, no mira los problemas del país desde la tribuna, sino que está dentro de la batalla por recuperar la dignidad de su país. Por tanto, pensar en el fantasma de la izquierda como la ideología que representa la verdadera democracia y la dignidad humana es necesario y urgente en estos tiempos turbulentos.

\section{CONCLUSIONES}

Hablar de democracia, significa dar el poder a la clase que es digno de ella: la mayoría existente en el Perú. Esa clase que, sin saber los conceptos elementales de la categoría en denominación, cumple cabalmente los ejercicios democráticos y la esencia que tiene aquella palabra. Por el contrario, la clase conservadora-centralista-racista a pervertido la nomenclatura del vocablo democracia, volviéndolo un simple adjetivo que es utilizado cada ves que surge la izquierda o algún grupo contrario a los intereses del poder.

Para poner fin al constructo, el Perú es una nación dividida que no encuentra espacios de convergencia entre las clases divergentes, $y$, los problemas son recurrentes si no preexiste el consenso necesario para poner una agenda plurinacional. En ese cause, queda comprobado que seguir la ideología de la derecha radical no es el camino, ya que, solo ha traído miedo, imposición, violación de los Derechos Humanos y muchas mentiras, induciendo así a la población al viejo cuento del crecimiento económico y disminución de la pobreza. En definitiva, solo queda una vía a seguir: apegarnos al fantasma de la izquierda en ascenso, conformado por millones de peruanos excluidos del sistema centralista, que hasta hoy claman justicia, libertad, dignidad y una reivindicación sociopoliticoeconómico total.

\section{REFERENCIAS BIBLIOGRÁFICAS}

Huanca-Arohuanca, J. W. (2019a). El despertar de una nueva era: colonización y camino hacia la revolución. Revista Revoluciones, 1(1), 1-3. http://revistarevoluciones.com/index.php/rr/article/view/1/2

Huanca-Arohuanca, J. W. (2019b). El discurso filosófico y la violencia política en la Nación Aymara - Ácora [Universidad Nacional del Altiplano]. http://repositorio.unap.edu.pe/bitstream/handle/UNAP/12758/Huanca_Arohuanca_Jesús_Wiliam.pdf?sequence $=1$ \&isAllowed $=\mathrm{y}$

Huanca-Arohuanca, J. W. (2020a). Caleidoscopio social al Covid-19: pánico y desesperación en tiempos de aislamiento. Revista Universidad y Sociedad, 12(6), 226-231. https://rus.ucf.edu.cu/index.php/rus/article/view/1836

Huanca-Arohuanca, J. W. (2020b). Contrahegemonía y la lucha por la educación en el sur del Perú. Editorial Académica Española.

Huanca-Arohuanca, J. W. (2020c). Cuando la muerte nos mira con deseo de llevarnos al tártaro. Revista Revoluciones, 2(2), 1-5. https://doi.org/10.35622/j.rr.2020.02.001

Huanca-Arohuanca, J. W. (2020d). Retropías y distopías de la educación en Puno. Revista Helios, 4(1), $270-271$. https://doi.org/10.22497/Helios.41.4116

Huanca-Arohuanca, J. W. (2021). Narrativas de guerra y resistencia: participación de la mujer austral del Perú en la Guerra del Pacífico. Encuentros. Revista de Ciencias Humanas, Teoría Social y Pensamiento Crítico, 13, 50-59. https://doi.org/http://doi.org/10.5281/zenodo.4395218

Huanca-Arohuanca, J. W., \& Geldrech, P. (2020). Planificación educativa y gestión pedagógica-estratégica-operacional en las instituciones del nivel inicial en el sur del Perú. Revista Conrado, 16(76), 369-376. https://conrado.ucf.edu.cu/index.php/conrado/article/view/1497

Huanca-Arohuanca, J. W., \& Núñez, L. (2020). Estimaciones y contrastes de la pandemia en Perú y en el contexto mundial. Educare Et Comunicare. Revista Científica de La Fcultad de Humanidades, 8(2), $10-20$. https://doi.org/10.35383/educare.v8i2.440

Huanca-Arohuanca, J. W., \& Pilco, N. (2021). Acciones revolucionarias en Ámérica Latina: Puno y el Alto Perú durante el proceso de independencia (1809-1825). Chakiñan. Revista de Ciencias Sociales y Humanidades, 14. https://doi.org/10.1590/SciELOPreprints.1364

Tineo-Zaga, Y., Casa-Coila, M. D., \& Huanca-Arohuanca, J. W. (2021). Gestión pedagógica y cultura organizacional en la Institución Educativa Andrés Bello de Yunguyo, Perú. Educación y Sociedad, 19(1), 153-169. http://revistas.unica.cu/index.php/edusoc/article/view/1695 